archives

of thermodynamics

Vol. 33(2012), No. 4, 67-90

DOI: $10.2478 / \mathrm{v} 10173-012-0028-6$

\title{
An investigation into the influence of different parameters on the onset of boiling in minichannels
}

\author{
MAGDALENA PIASECKA*
}

Kielce University of Technology, Faculty of Mechatronics and Machine Building, 10-lecia P.P.7, 25-314 Kielce, Poland

\begin{abstract}
The paper presents experimental studies on boiling heat transfer in rectangular minichannels. The investigations focus on the transition from single phase forced convection to nucleate boiling, i.e., in the zone of boiling incipience. The experiment has been carried out with FC-72, R-123 and R-11 at the Reynolds number below 4700, corresponding to mass flow rate range $95-710 \mathrm{~kg} /(\mathrm{m} \mathrm{s})$. The main part of the test section is a minichannel of pre-set depth from 0.7 to $2 \mathrm{~mm}$ and width $(20,40$ and $60 \mathrm{~mm}$ ), with different spatial orientations from vertical to horizontal and $30 \%$ inclination angle adjustment. The objective of the paper includes the impact of selected parameters (liquid flow velocity, pressure and inlet liquid subcooling, channel dimensions and spatial orientation) on the boiling incipience in minichannels. The investigations are intended to develop a correlation for the calculations of the Nusselt number under the conditions of boiling incipience in the minichannel as a function of changeable parameters.
\end{abstract}

Keywords: Heat transfer; Flow boiling; Incipience (onset) of boiling

\section{Nomenclature}

$$
\begin{array}{lll}
B I & - & \text { boiling incipience } \\
\mathrm{Bo} & - & \text { boiling number } \\
G & - & \text { mass flux, } \mathrm{kg} /\left(\mathrm{m}^{2} \mathrm{~s}\right) \\
\mathrm{H} & - & \text { depth of the minichannel, } \mathrm{m} \\
\mathrm{Nu} & - & \text { Nusselt number }
\end{array}
$$

${ }^{*}$ E-mail address: tmpmj@tu.kielce.pl 


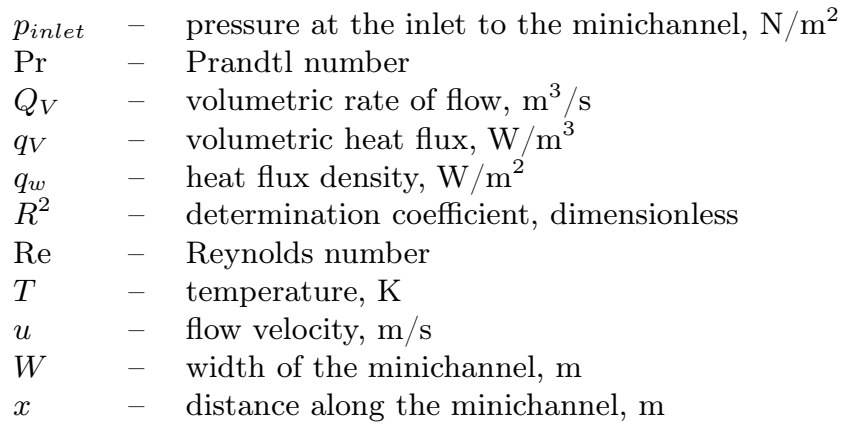

Greek symbols

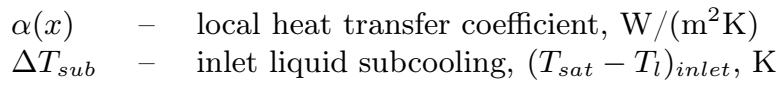

\section{Subscripts}

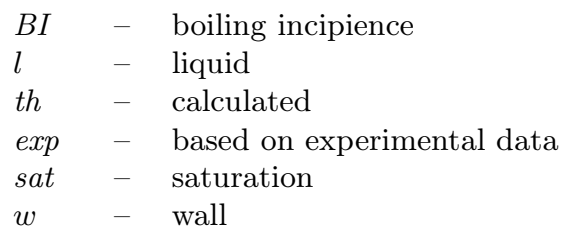

\section{Introduction}

Boiling is an extremely efficient heat transfer process used in power engineering, chemical engineering and nuclear engineering. One of the relevant boiling features is the high value of the heat transfer coefficient, enabling transport of large heat fluxes. Mini heat exchangers are used with the aim of providing higher cooling capability for new technologies. It means a reduction of their size and cost for an identical power. Owing to the change of state which accompanies flow boiling in minichannels, it is possible to meet contradictory demands simultaneously, i.e., to obtain a heat flux as large as possible at small temperature difference between the heating surface and the saturated liquid and, at the same time, retain small dimensions of heat transfer systems. Following the classification by Kandlikar et al. minichannels are fluid channels with small hydraulic diameter between $200 \mu \mathrm{m}$ and $3 \mathrm{~mm}[1]$.

Boiling incipience is not only a general problem in boiling but also a practical one in the evaluation of the safety of, for example, electronic equipment or nuclear reactors. It is known that under certain conditions, there can occur a considerable rise in wall temperature above the satura- 
tion temperature before boiling begins. This 'temperature overshoot' called 'superheated excursion', or 'nucleate hysteresis' is conspicuous when highly wetting dielectric fluids (as refrigerants) are used.

\section{Brief review of literature}

Review of relevant literature and the selected publications covering heat transfer and flow patterns in rectangular minichannels is presented in [2-4].

Nucleation hysteresis for boiling on smooth surfaces was discovered by Corty [5] and van Camp [6]. Numerous results of experimental investigations and attempts of their theoretical explanation, both for pool boiling and flow boiling were presented in review paper by Bräuer and Mayinger [7] and Bar-Cohen [8]. Bilicki [9,10], Bohdal and Czapp [11], and Bohdal [12] conducted experimental investigations of zero boiling crisis (nucleation hysteresis) in refrigerant flow boiling. A thermodynamic analysis demonstrated that nucleation hysteresis is caused by latent heat transported by vapor bubbles forming in the liquid adjacent to the walls which act as heat sinks. Celata et al. [13] proposed describing hysteresis with a hysteresis coefficient dependent on the heating surface temperature drop and maximum superheat for the boiling incipience.

The results of investigations of heat transfer flow boiling conducted on test sections with rectangular, vertical, uniformly heated minichannels, at the flow of distilled water and/or methanol were presented in the studies of Peng and co-workers [14-17]. Orozco and Hanson, [18], investigated boiling in asymmetrically heated minichannels of various depths $(1.59-25.4 \mathrm{~mm})$, inclined at different angles. Hollingsworth et al. [19-21], dealt with heat transfer in R-11 flow through $1 \mathrm{~mm}$ deep vertical minichannel. Liquid crystal thermography was used to acquire the wall temperature data for forced convection in an asymmetrically heated channel. Ammerman and You [22] studied FC-87 flowing through an asymmetrically heated horizontal minichannel of different square cross-sections with sides of 2,1 and $0.5 \mathrm{~mm}$. Wambsganss et al. identified the flow patterns occurring in flow boiling in minichannels, both circular and rectangular [23-25]. In [26], the authors investigated flow boiling heat transfer characteristics of water and hydrocarbons in mini- and microchannels. Infrared (IR) thermography was employed for determining wall temperatures. The analysis of flow boiling heat transfer in a rectangular minichannel of $0.5-4 \mathrm{~mm}^{2}$ cross-sections was discussed in [27]. In [28] the authors focused on friction and heat transfer coefficients 
in two-dimensional minichannels of $1.12 \mathrm{~mm}$ to $300 \mu \mathrm{m}$ in thickness. In [29] the authors presented the results of investigations of heat transfer at water boiling in rectangular minichannels with hydraulic diameters of 2.67 and $0.8 \mathrm{~mm}$ at atmospheric pressure. Experimental research on flow boiling heat transfer, pressure drop and flow patterns in rectangular narrow channels is discussed in [30], including the experiments on flow boiling of water in a rectangular vertical channel of 0.86 and $2.0 \mathrm{~mm}$. In [31], an experimental study of friction factor and heat transfer coefficient for a vertical liquid up-flow of R-134a was presented. The studies employed a flat multiport extruded tube composed of 11 parallel rectangular channels $(3.28-1.47 \mathrm{~mm})$. The three exhaustive, critical and different reviews by Kandlikar [32,33]. Tadrist [34,35] and Thome [36] present the current knowledge of boiling heat transfer in minichannels in many aspects, including boiling incipience phenomenon, the impact of selected parameters on boiling heat transfer in minichannels and numerical methods to solve heat transfer problem.

Wide experimental investigations and theoretical studies on heat transfer in minichannels in Poland were conducted by J. Mikielewicz, D. Mikielewicz [37-40] and K. Dutkowski [41-44].

Summarizing, an abundance of literature has appeared on heat transfer experimental investigations and results analyses of flow boiling heat transfer in minichannels of various dimensions. Unfortunately, local heat transfer coefficients and boiling curves, obtained as a result of experimental investigations and theoretical analyses, including correlations, demonstrate high scatter. The measurements were taken for a rather small variability range of parameters such as the flow velocity, pressure and liquid subcooling. The literature of the subject offers no generalized or universal correlations which would allow prediction of heat transfer for minichannels of various geometry and spatial orientation.

\section{Experimental set-up}

\subsection{The main loop}

In the main loop for the boiling process examination, Fig. 1, the cooling liquid, i.e., FC-72, R-123 or R-11, flows. The experimental investigation was conducted at two set-ups. The majority of experiments were carried out at the main set-up, as described in [45], in the paper referred to as the first set-up. Preliminary experiments were performed at the new experimental set-up, in the paper referred to as the second, whose flow and auxiliary 
cycles were miniaturized and modernized in comparison to the previously used set-up. The cycle was generally simplified, and - simultaneously prepared for performance of a wide spectrum of experiments as well as being adapted to environmental protection requirements. In the second set-up a bleeding loop with a deaerator was added, which helps remove the air from the system in a fast and effective way, and ensures that single-phase liquid flows into the test section.

a)

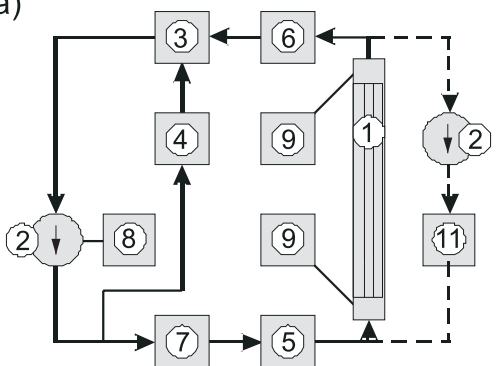

— main loop (working fluid) b)

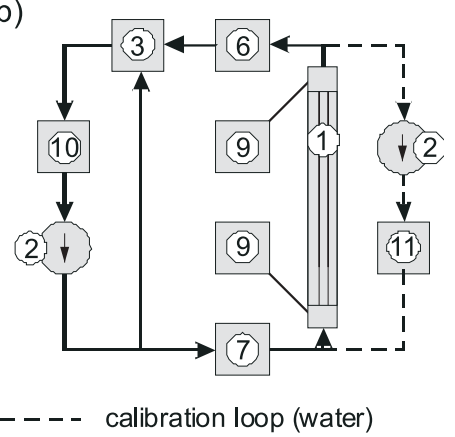

Figure 1. The schematic diagrams of the loop in the flowing system: a) the first experimental stand, b) the second experimental stand; 1 - test section with a minichannel; 2 - rotary pump; 3 - compensating tank/pressure regulator; 4, 5 - plate-type heat exchangers; 6 - tube-type heat exchanger, 7 - rotameters; 8 - frequency inverter, 9 - pressure converter, 10 - deaerator, 11 - heater.

The main flow loop of both experimental stands, besides the most important part, i.e., the test section, consists of following elements: a rotary pump, heat exchangers, pressure regulator/compensating tank. The most important set-up elements for the flow, pressure and temperature control and measurement are: rotameters, pressure converters and type $\mathrm{K}$ thermocouples. The calibration loop is used to detect of temperature values corresponding to the hues observed on the surface covered with liquid crystals. The schematic diagrams of both main loops of the flowing system, as well as calibration loop are presented in Fig. 1.

\subsection{The test section}

The essential part is the test section with a minichannel (Fig. 2, 1) of preset depth from 0.7 to $2 \mathrm{~mm}$ and width (20, 40 or $60 \mathrm{~mm}$ ) and $360 \mathrm{~mm}$ length, which has different inclination angle with respect to the horizontal line (spatial orientations of the test section are from vertical to horizontal with 
min. 30\% inclination angle adjustment). The heating element for working fluid (R-11, R-123, FC-72) which flows along the minichannel (1) is a thin alloy foil (2) stretched between two covers. This foil of $0.1 \mathrm{~mm}$ depth is designated as Haynes-230, made of Ni-Cr-W-Mo high-temperature alloy. It is powered by a generator, e.g., thyristor converter or inverter welder acting as a regulated DC power supply.

a)

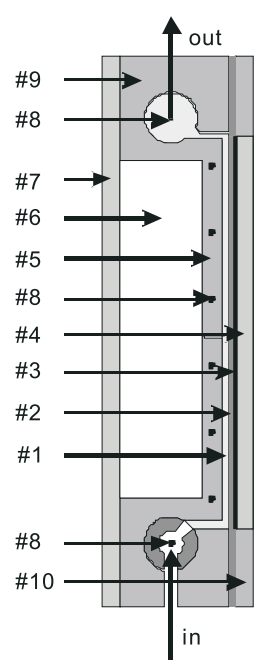

b)

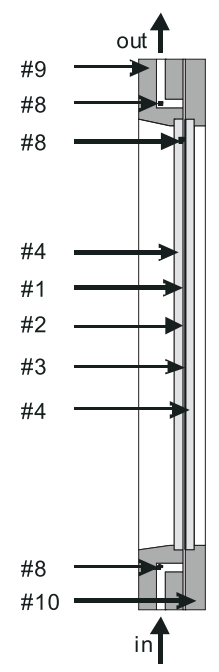

c)

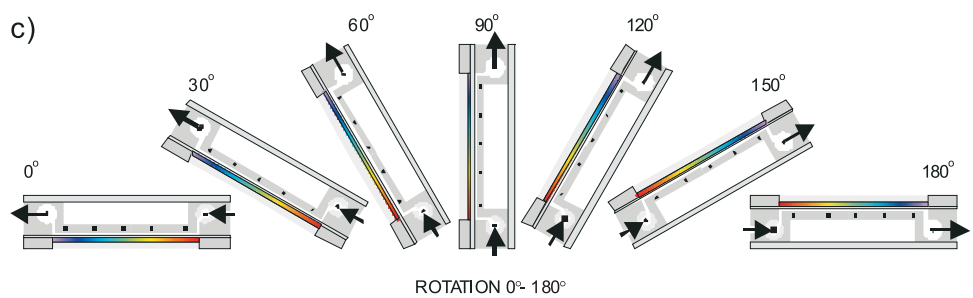

Figure 2. The schematic diagrams of the test section: a) the first experimental stand, b) the second experimental stand; 1 - minichannel, 2 - heating foil, 3 - liquid crystal layer, 4 - glass sheet, 5 - quasiadiabatic wall, 6 - water channel, 7 - rear cover, 8 - chamber, 9 - channel body, 10 - front cover; c) spatial orientations of the minichannel.

In the first experimental stand, the test section rear cover (Fig. 2a, 7) protects the channels in the channel body (9), to which water is fed (6) or which are air gaps. Due to these auxiliary channels it is possible to maintain the desirable temperature on the wall which is treated as quasiadiabatic (5). There are five thermocouples soldered to the bottom wall of the water 
channel and two others located of the auxiliary chamber inlet and outlet (8). It is possible to observe a surface of the minichannel opening covered with a glass sheet (4) as well as the changes in the colour of foil surface through the glass. This side of the heating foil is covered with a base coat and liquid crystal paint (3). In the second experimental stand the opposite surface of the minichannel can be observed through the other glass, which helps to recognize the gas-liquid two-phase flow patterns. The issues of flow patterns identification are the focus of other articles [2]. In the test section of both experimental stands, the minichannel inlet and outlet is equipped with some thermocouples and two pressure converters. Spatial orientations of the test section with a minichannel, from vertical to horizontal, setting up during experiments are presented in the Fig. 2c.

\subsection{The colour image and data acquisition system}

If liquid crystals are to be used to take measurements of the foil surface temperature distribution, it is necessary to have a complex colour image and data acquisition system shown in Fig. 3. Recording temperature distribution on the surface under examination at the first experimental stand (Fig. 3a) is performed by Pulnix CCD colour video camera (3), equipped with the device decomposing video signal into the RGB signal (6), video recorder (7) with monitor (8) and PC with frame grabber (9). The software working with frame grabber and the software for processing the measurement data complement the system. The remaining measurement data are recorded with Keithley 500 A data acquisition station equipped with ViewDac software, installed on another computer. In the second experimental stand Canon G-11 (5) digital camera and Canon D550 digital SLR camera (4) are used (Fig. 3b). DaqBoard 2000 data acquisition station (10) equipped with DASYLab software completes the data acquisition system. In both experimental stands the illumination system consists of several fluorescent lamps (2) emitting 'cool white light'.

\section{Experiment}

The observation of the two-dimensional temperature distribution on the heating surface of the minichannel is possible owing to the liquid crystal thermography [46]. The temperature distribution is measured on the basis of hue distribution on the heating surface covered with liquid crystals. 
a)

b)

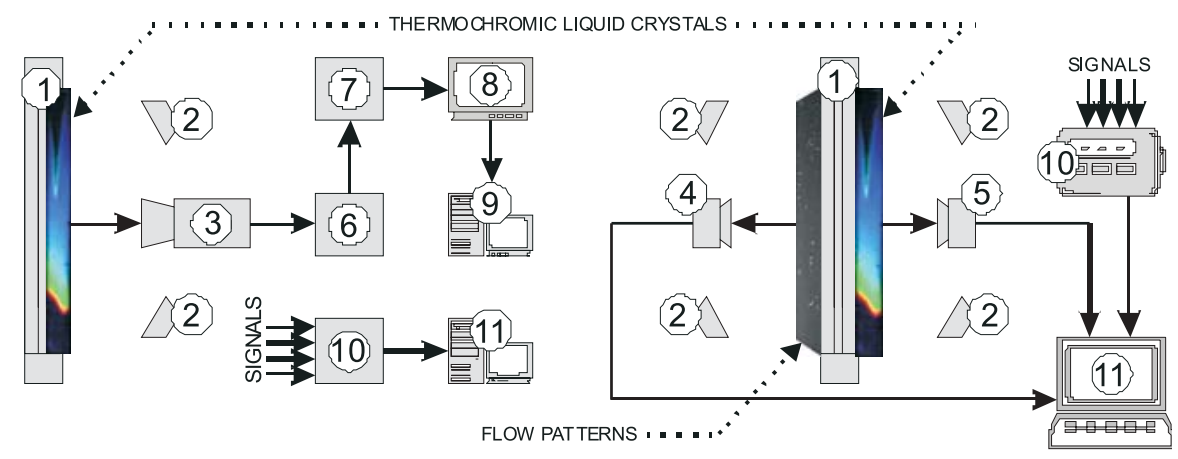

Figure 3. Diagrams of the data and color image acquisition system: a) the first experimental stand, b) the second experimental stand; 1 - test section, 2 - lighting system, 3 - CCD video camera, 4 - digital camera, 5-digital SLR camera, 6 - RGB signal decomposer, 7 - Betacam recorder, 8 - monitor, 9 - computer with frame grabber and monitor, 10 - data acquisition station, 11 - computer with monitor.

A calibration procedure has to precede the boiling heat transfer investigation. Its aim is to assign corresponding temperature values to the hues observed on the surface covered with liquid crystals.

In the experimental conditions subcooled liquid flows laminarly into the asymmetrically heated minichannel. In the beginning, when the heat flux increases, the heat transfer between the heating foil and the liquid proceeds as single phase forced convection (Fig. 4, images from 1 up to 3). In the foil adjacent area the liquid becomes superheated, whereas in the flow core and close to the quasiadiabatic surface it remains subcooled. It means that a large temperature gradient is found along a small depth of the minichannel. In the foil adjacent area the liquid becomes superheated, whereas in the core of the flow and close to the quasiadiabatic surface it remains subcooled. In the further part of the experiment the increase in the heat flux results in vapour nuclei activation along the channel heating surface. Further increase in the electric power supplied to the heating foil causes boiling incipience in the minichannel, point BI (images from 4 up to 11). Spontaneous nucleation causes the heating surface temperature drop for the constant heat flux. This jumplike heating surface temperature results from vapour bubbles spontaneous formation in the wall adjacent layer. They are acting as internal heat sinks, absorbing a significant amount of energy transferred to the liquid $[2-4,10,12,47]$. The 'boiling front' is recognizable 
as the hue sequence pattern, which indicates a gradual hue changes to the liquid crystals (in accordance with the spectrum sequence) and next sharp hue changes in the liquid crystals (inversely to the spectrum sequence). Outof-sensitivity-range temperatures are shown in black. The boiling incipience is identified with the maximum value of the heating surface temperature in 'boiling front' image. A sharp temperature drop follows further out.
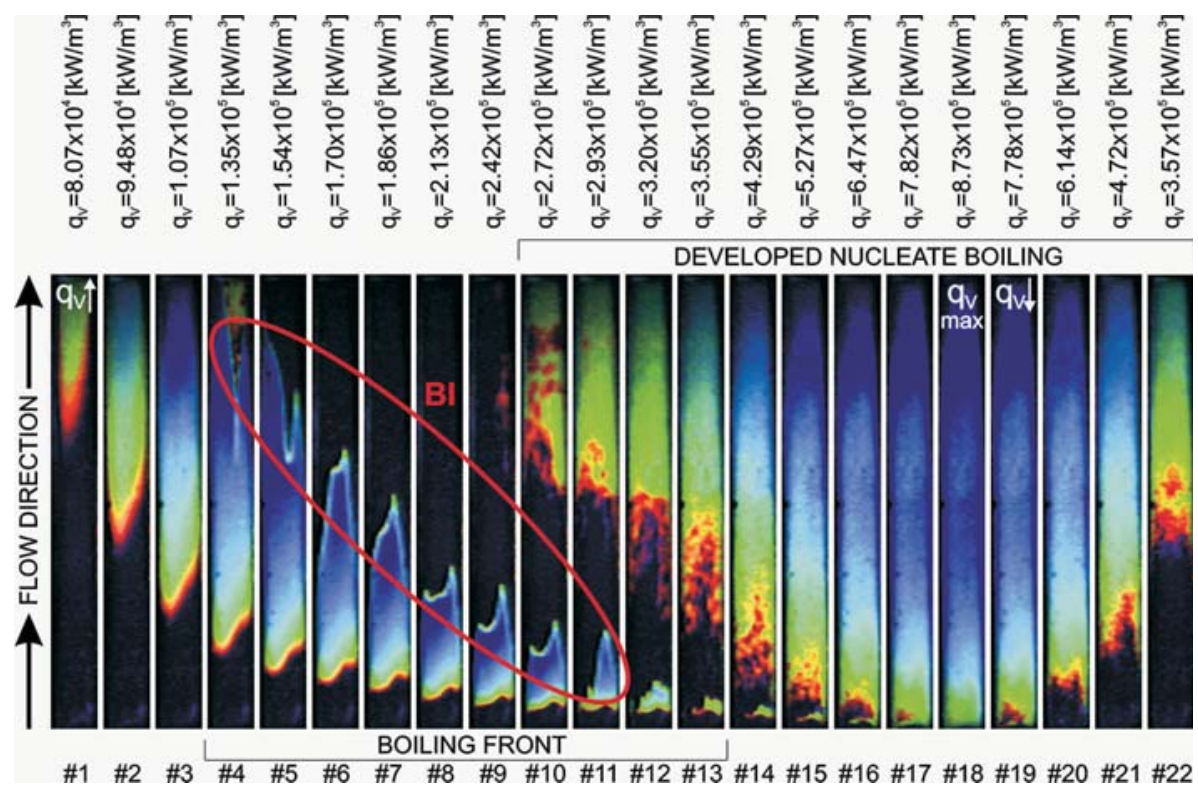

Figure 4. Exemplary images of hue temperature distribution on the minichannel heating wall while initially increasing (from 1 up to 18) and further decreasing (from 19 up to 22) heat flux supplied to the heating surface; the first set-up, vertical minichannel: $H=1 \mathrm{~mm}, W=40 \mathrm{~mm}, \mathrm{R}-123$, experimental parameters: flow velocity $0.28 \mathrm{~m} / \mathrm{s}$, mass flux $412 \mathrm{~kg} /\left(\mathrm{m}^{2} \mathrm{~s}\right), p_{\text {inlet }}=180 \mathrm{kPa}, T_{\text {sub }}=33 \mathrm{~K}$.

The following data for the ten initial settings (from 1 up to 10) in Fig. 5 is presented successively: heating foil temperature a); fluid temperature b); and saturation temperature c); and dependencies on the distance along the minichannel length. Heat transfer coefficient dependence on the distance along the minichannel length for setting 6 is presented in Fig. 6b, corresponding to heating foil temperature in Fig. 6a. Charts show BI position.

In the first experimental stand, on the surface of the minichannel quasiadiabatic wall, constant temperature is maintained (arithmetic mean of the fluid temperature at the inlet and outlet of the minichannel) while a supplementary loop carries water of regulated temperature and flow rate to 

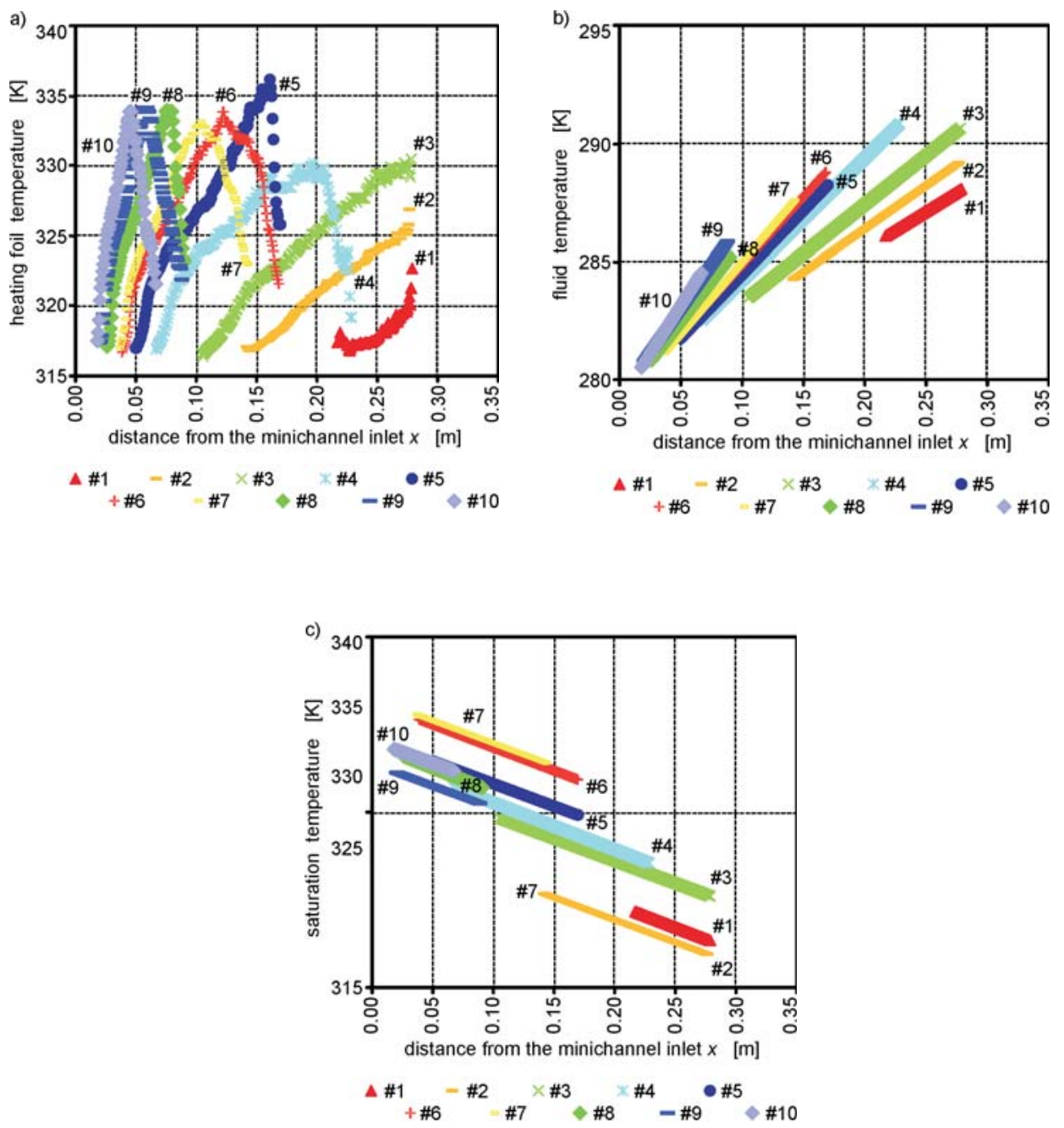

Figure 5. Exemplary images of hue temperature distribution on the minichannel heating wall while initially increasing (from 1 up to 18) and further decreasing (from 19 up to 22) heat flux supplied to the heating surface; the first set-up, vertical minichannel: $H=1 \mathrm{~mm}, W=40 \mathrm{~mm}$, R-123, experimental parameters: flow velocity $0.28 \mathrm{~m} / \mathrm{s}$, mass flux $412 \mathrm{~kg} /\left(\mathrm{m}^{2} \mathrm{~s}\right), p_{\text {inlet }}=180 \mathrm{kPa}, T_{\text {sub }}=33 \mathrm{~K}$. 

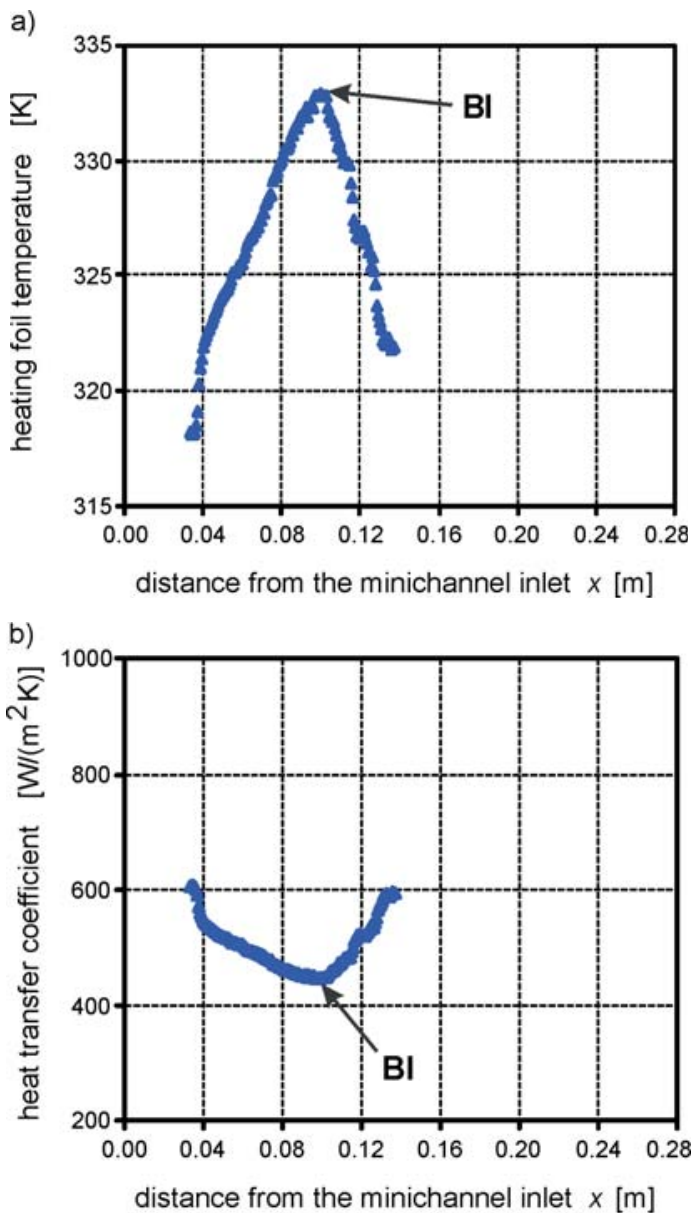

Figure 6. Examples of heating foil temperature a), and b) heat transfer coefficient dependence versus the distance from the minichannel inlet, both for image 6 (see Fig. 4).

the water channel (see Fig. 2a). When the heat flux continues to increase (Fig. 4, images from 10 up to 18), black hue is replaced with a new hue sequence in the upper part of images. This occurs when developed nucleate boiling is in progress in the minichannel. Then the current supplied to the foil is gradually reduced (images from 19 up to 22). Mild hue changes, in the direction opposite to the spectrum sequence, are observed to accompany the decrease of current supplied to the foil. As a result, heat transfer returns to forced single phase convection. 
The variation range of parameters characterising experimental investigations is presented in Tab. 1.

Table 1. The variation range of basic parameters in experimental investigations.

\begin{tabular}{|c|c|c|}
\hline Parameter & Unit & Value \\
\hline \hline$Q_{V}$ & $\mathrm{~m}^{3} / \mathrm{s}$ & $2.55 \times 10^{-6}-1.00 \times 10^{-4}$ \\
\hline$p_{\text {inlet }}$ & $\mathrm{kPa}$ & $126-45$ \\
\hline$q_{V}$ & $\mathrm{~kW} / \mathrm{m}^{3}$ & $663 \times 10^{2}-117 \times 10^{4}$ \\
\hline$q_{w}$ & $\mathrm{~kW} / \mathrm{m}^{2}$ & $6.7-118.8$ \\
\hline$\Delta T_{n}$ & $\mathrm{~K}$ & $30.9-0.4$ \\
\hline$u$ & $\mathrm{~m} / \mathrm{s}$ & $0.06-0.40$ \\
\hline$G$ & $\mathrm{~kg} /\left(\mathrm{m}^{2} \mathrm{~s}\right)$ & $95-10$ \\
\hline $\mathrm{Re}$ & - & $459-4657$ \\
\hline
\end{tabular}

Pressure measurements in the inlet and outlet are performed with the accuracy of $\pm 0.1 \%$ of full scale. The flow rate is measured using the rotameters with the accuracy of $\pm 2 \%$ of full scale. Evaluation of the accuracy of heating foil temperature measurements with liquid crystal thermography were discussed in $[2,3,46]$. Mean temperature measurement error of heating foil by liquid crystal thermography equal to $0.86 \mathrm{~K}$ was obtained. The value of the relative volumetric heat flux measurement error amounted to $3.53 \%$ [2] and $2.04 \%$ [3]. A detailed discussion of heat flux and heat transfer coefficient errors are discussed in detail in [45].

\section{$5 \quad$ Experimental results}

\subsection{Main elements for data analysis}

The analysis of the impact of selected factors, e.g., the inlet pressure, inlet liquid subcooling and liquid flow velocity, minichannel geometry and spatial orientation on boiling incipience in flow through minichannels has been made with the consideration of:

- 'boiling front' images accompanying boiling incipience and the heating foil dependence determined from hue distribution on that surface Fig. 4,

- heat transfer coefficient dependence on the distance along the minichannel length, corresponding to heating foil temperature. 
Owing to the solution of the inverse problem, in which - with the application of temperature measurement at the system internal points (temperature distribution on the heating foil on the side of the glass) and the measurement of the electric power supplied to the heater - the sought local heat transfer coefficients on the heating wall surface contacting the boiling fluid can be calculated. The local heat transfer coefficient is determined with the use of one- and two-dimensional models of heat transfer through foil and glass $[2-4,45]$. A detailed discussion of heat transfer coefficient determination can be found in [45]. Exemplary data are shown in Fig. 6.

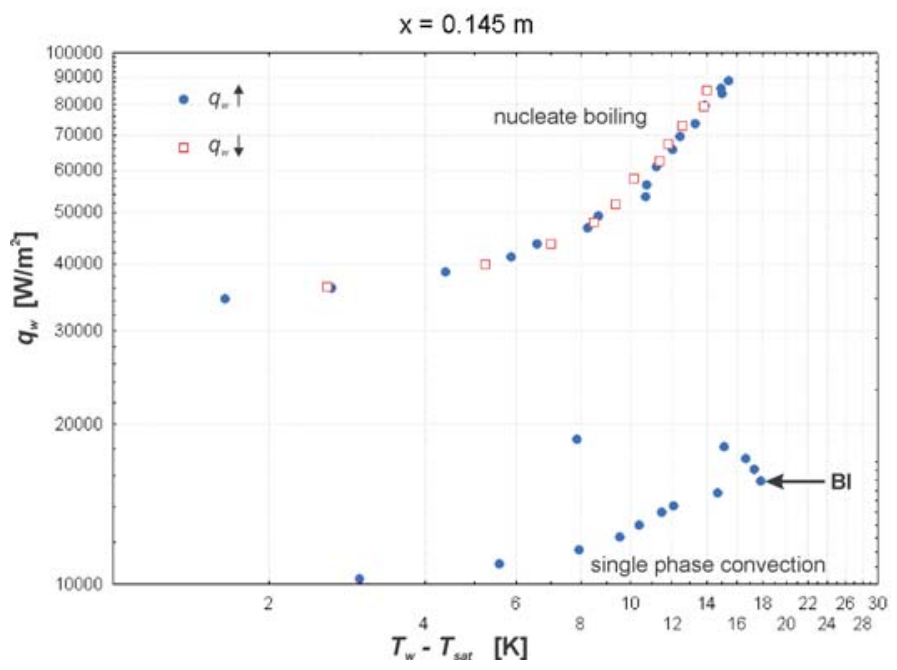

Figure 7. Boiling curve, for the distance $0.145 \mathrm{~m}$ from the minichannel inlet, data as in Fig. 4.

According to the experimental results presented as a boiling curve (Fig. 7) it was observed that boiling incipience in minichannels is accompanied by the occurrence of 'nucleation hysteresis' phenomenon. It is characteristic of the boiling of a liquid with a small wetting angle. It involves a considerable heating surface temperature drop. The appearance of boiling incipience is associated with the activation of some nuclei on the heated wall. It manifests itself as the sudden decrease in the wall temperature, as bubbles behave like heat sinks. That results in the diminishing of the local heating surface temperature $[2-4,10,12,47]$. 


\subsection{Influence of the selected parameters on boiling incipience}

The analysis of the impact of selected parameters on boiling incipience was conducted on the basis of experimental results at varying parameters, for different geometry and spatial orientation of the minichannel. For all experimental results it can be noticed that in the minichannel flow boiling, considerable heat transfer enhancement takes place at boiling incipience. It is observed as a sharp increase in the heat transfer coefficient, as shown in Fig. 6b. Generally, it was observed that higher heat transfer coefficients appeared when higher heat fluxes were supplied to the heating surface at boiling incipience, as can be observed in Fig. 8 .

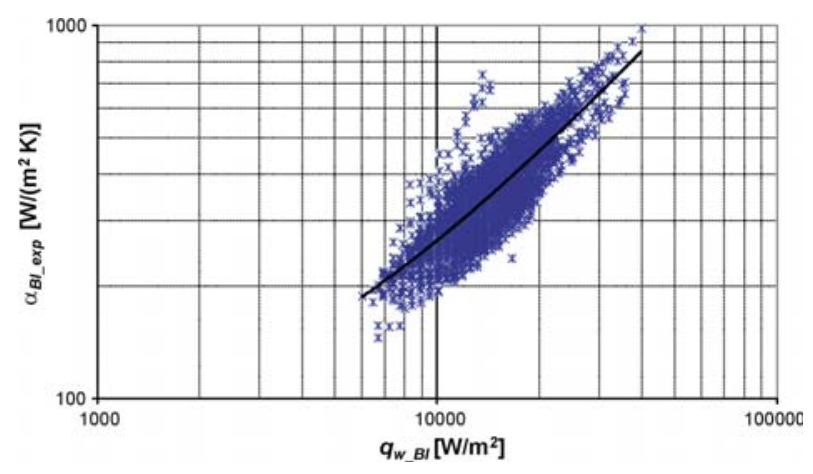

Figure 8. Heat transfer coefficient versus heat flux density dependence for BI.

\subsubsection{Influence of the pressure at the inlet on BI}

The analysis of the impact of the pressure at the inlet to the minichannel on boiling incipience was conducted on the basis of some examples grouped in series. Each series covered experiments performed at various pressures at the minichannel inlet and the same liquid flow velocity in the channel of the same geometry. While analyzing the impact of the inlet pressure on boiling incipience, it may be noted that:

- no significant impact of inlet pressure on values of heat transfer coefficients at boiling incipience has been observed;

- in spite of increasing pressure in the system, the nucleate boiling incipience begins at almost constant distance from the channel inlet 
in vertical minichannels, while in inclined minichannels the distance between the 'boiling front' and the minichannel inlet increases;

- the higher the pressure at the channel inlet, the longer the sector of the channel where the 'boiling front' is observed;

- the higher the pressure at the channel inlet, the greater the temperature drop to be observed in the heating surface temperature at hysteresis, which has been recorded for vertical minichannels for $\operatorname{Re}>1000$, and was most conspicuous in the inclined minichannels at the position of $150^{\circ}$.

\subsubsection{Influence of the liquid subcooling at the inlet on BI}

The analysis of the impact of the liquid subcooling at the inlet to the minichannel on boiling incipience was conducted on the basis of some examples grouped in series. Each series comprises two examples of experiments conducted at varying inlet liquid subcooling, with the remaining investigation parameters maintained at the same level (liquid flow velocity and minichannel inlet pressure, minichannel geometry). On the basis of the data analysis of the impact of the liquid subcooling at the inlet to the minichannel on boiling incipience, it has been observed that:

- the heat transfer coefficient at boiling incipience does not noticeably affect liquid subcooling to saturation temperature at the minichannel inlet and the distance where the 'boiling front' occurs is practically constant, varying negligibly;

- the higher the values of the liquid subcooling at the channel inlet with respect to the saturation temperature, the higher the heat flux values at which the 'boiling fronts' occur, accompanied by the lowering values of the temperature drop.

\subsubsection{Influence of the liquid flow velocity at the inlet on BI}

The analysis of the impact of the liquid flow velocity in the minichannel on boiling incipience was performed in the same fashion, on the basis of selected examples grouped in series. Each series comprised experiments carried out at approximate values of pressure at the minichannel inlet and different liquid flow velocities for the same minichannel geometry. On the basis of results analysis, it has been found that: 
- increasing the liquid flow velocity in the minichannel results in an increase in local heat transfer coefficients for boiling incipience, with the increasing liquid flow velocity, boiling incipience in the channel begins at increasing distance from the inlet;

- the higher the liquid flow velocity, the higher the temperature drop in boiling incipience at boiling incipience;

- in some observed cases, with the increasing liquid flow velocity, the 'boiling front' is to be noticed over a longer sector of the channel, but the results of some of the experiments have not corroborated this observation (particularly in the case of inclined minichannels: for instance, at the $60^{\circ}$ position the velocity increase has no impact on the distance between the 'boiling front' occurrence and the channel inlet);

- for low flow velocities, for Re $<1000$ and low inlet pressures, $p_{\text {inlet }}<$ $230 \mathrm{kPa}$, the 'boiling front' is very unstable; under these conditions boiling incipience is characterized by small drops in the heating surface temperature, which occur over a very short channel sector; at the same time local heat transfer coefficients reach low values.

\subsubsection{Influence of the minichannel depth on BI}

An analysis of the impact of channel depth on boiling incipience brought inconsistent results. By adjusting the minichannel depth, it is very difficult to obtain boiling incipience at similar flux (the same pressure and velocity conditions). Figure 9 shows the local heat transfer coefficient as a function of heat flux for minichannels of different depths and the same width $(40 \mathrm{~mm})$ for experiments with the use of R-123. It may be also observed that heat transfer coefficient values at boiling incipience become higher as the minichannel depth increases, but only at heat flux density values above $20000 \mathrm{~W} / \mathrm{m}^{2}$. 


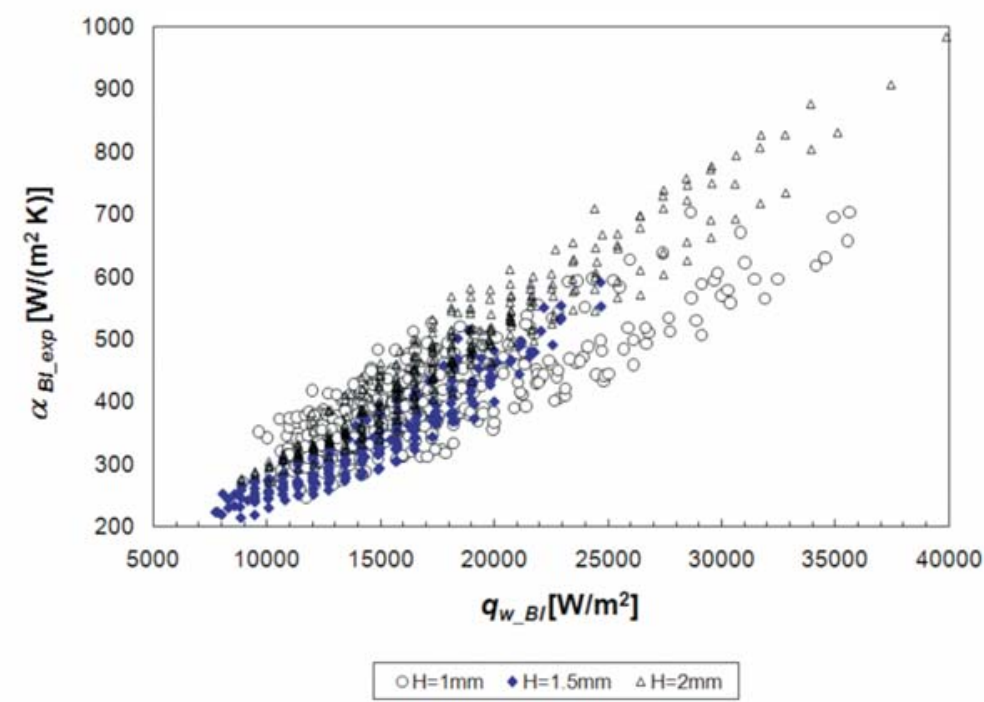

Figure 9. Heat transfer coefficient dependence versus boiling heat flux density for the vertical minichannel of different depths: $W=40 \mathrm{~mm}, \mathrm{R}-123$, data for BI.

\subsubsection{Influence of the minichannel spatial orientation on BI}

While adjusting the minichannel spatial orientation from the top horizontal to the bottom horizontal position, the following observations have been made:

- in the bottom horizontal minichannel position and at $150^{\circ}$, at negligible liquid flow velocities in the minichannel, the increase in the number of nucleate boiling incipience areas (rather than the usual single, easily recognisable area, as is the case with positions close to the vertical) has been observed; the length of the sector where a drop in the heating surface temperature occurs to accompany boiling incipience decreases markedly;

- at minichannel positions in which the fluid flowing along the minichannel is placed on the heating surface (bottom, e.g., $150^{\circ}$ ), a higher drop in the heating surface temperature and higher value of the heat transfer coefficient at boiling incipience has been observed, as compared to positions in which the fluid is placed below the heater surface (top, e.g., $\left.30^{\circ}\right)$. 


\subsubsection{Influence of the kind of cooling liquid on BI}

Figure 10 presents the heat transfer coefficient versus heat flux density dependence for the vertical minichannel of the same depth and width (two series) for different cooling liquids. Both examples: for R-123 and R-11, and for R-123 and FC-72, with the same minichannel dimensions, have yielded similar results.

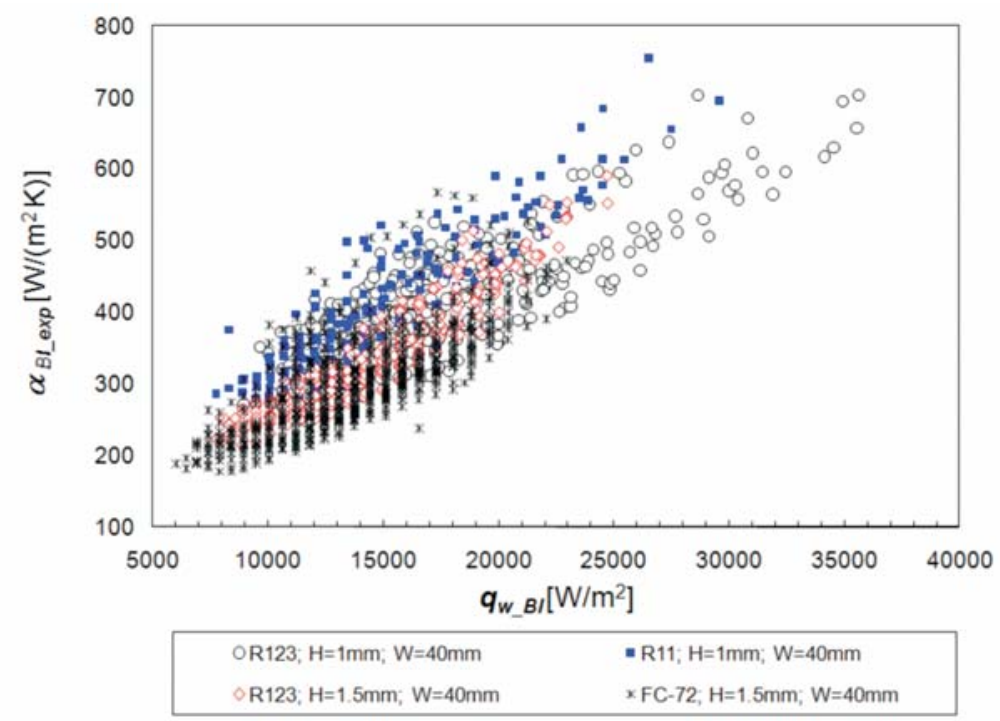

Figure 10. Heat transfer coefficient versus heat flux density dependence for the vertical minichannel, obtained for different cooling liquids, data for BI.

\subsection{Correlations}

In order to estimate the values of regression parameters, 2384 measurement results for nucleate boiling incipience in the minichannels of $0.7-2 \mathrm{~mm}$ depth, 20-40 mm width and different spatial orientation, with using FC-72, R-123 and R-11 and were accounted for. The data was collected for boiling incipience BI points, where the constant heat flux was supplied to the heating surface. They were obtained on the basis of experiments carried out in the first set-up.

In accordance with the requirements of dimensional analysis, the dependence for the Nusselt number was as follows:

$$
\mathrm{Nu}_{B I_{-} t h}=4.7 \operatorname{Re} \times \mathrm{Bo}^{0.9} \operatorname{Pr}^{0.2} .
$$


The Nusselt number calculated from (1), $\mathrm{Nu}_{B I_{-} t h}$, was compared with the Nusselt number determined experimentally, $\mathrm{Nu}_{B I}$ exp , in Fig. 11. Standard errors of the calculated Nusselt number amount to approx. 0.07. Determination coefficient, $R^{2}$, is the measure of regression line matching accuracy (in the logarithmic system) and has the of value 0.95 . The equation demonstrated congruence with over $89 \%$ of observable 'boiling fronts', the tolerance being $\pm 25 \%$. This dependence refers to the following ranges of similarity numbers:

$\begin{array}{lll}2.76 & \leq \mathrm{Nu}_{B I} \leq & 46.42, \\ 387 & \leq \mathrm{Re} \leq & 4703, \\ 9.78 \times 10^{-5} & \leq \mathrm{Bo} \leq & 1.92 \times 10^{-3}, \\ 2.86 & \leq \mathrm{Pr} \leq & 13.54\end{array}$

The definitions for the determination of the dimensionless numbers (Nusselt, Reynolds, Boiling and Prandtl numbers) used in the correlation have been based on the literature, eq., [48].

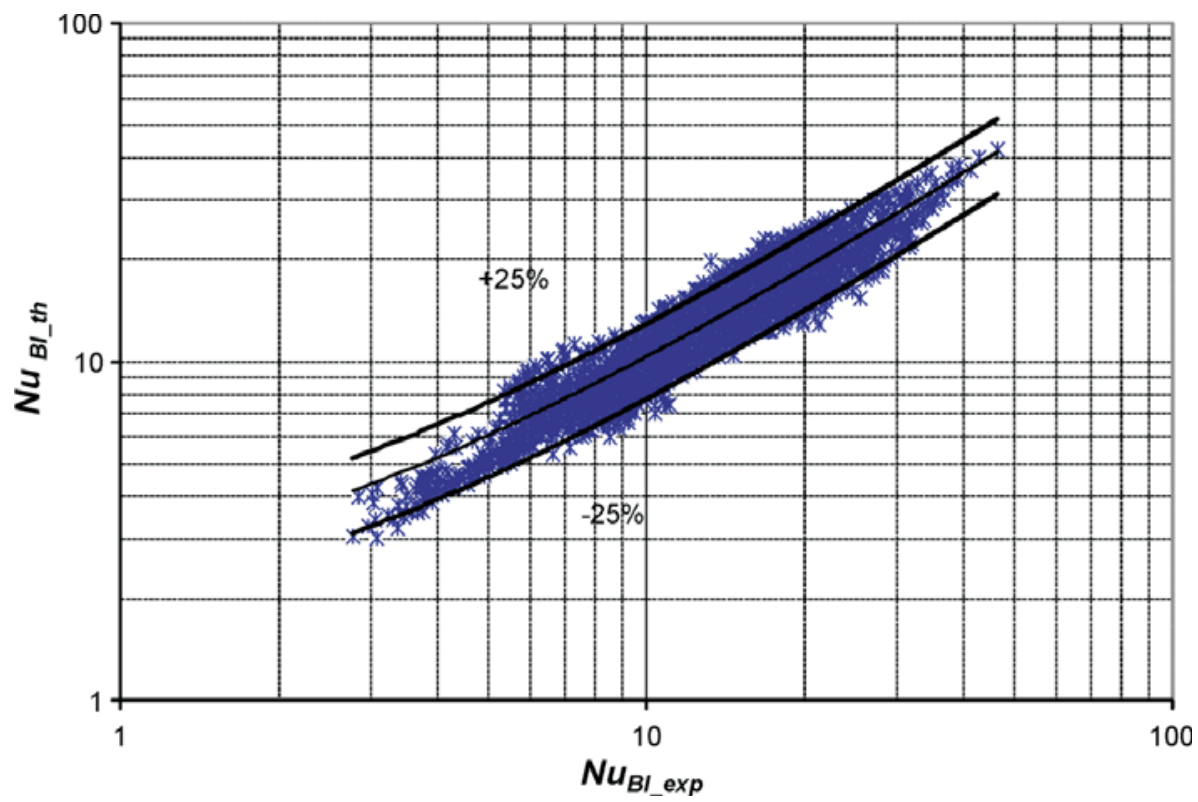

Figure 11. Correlation Eq. (1) for predicting boiling incipience in the minichannel.

At the same time, on the basis of experimental data and regression analysis, a reduced equation was developed

$$
\alpha_{B I_{-} t h}=0.2 q_{w_{-} B I}^{0.8} .
$$


Equation (2) should be treated as engineering dependence for the calculations of heat transfer coefficient on the basis of known heat flux density, for FC-72, R-123 and R-11 boiling incipience in a minichannel. In this relation $q_{w}$ is the heat flux density in $\mathrm{W} / \mathrm{m}^{2}$ and the heat transfer coefficient $\alpha$ is in $\mathrm{W} /\left(\mathrm{m}^{2} \mathrm{~K}\right)$. Heat transfer coefficient calculated from Eq. (2), was compared with determined experimentally in Fig. 12. Equation (2) is congruent, at $\pm 25 \%$ tolerance, with measurement results for over $91 \%$ of data. It was derived for heat flux densities and heat transfer coefficients characteristic of boiling incipience of the range: $6 \leq q_{w_{-} B I} \leq 40 \mathrm{~kW} / \mathrm{m}^{2}$; $145.6 \leq \alpha_{B I_{-} \exp } \leq 983.2 \mathrm{~W} /\left(\mathrm{m}^{2} \mathrm{~K}\right)$.

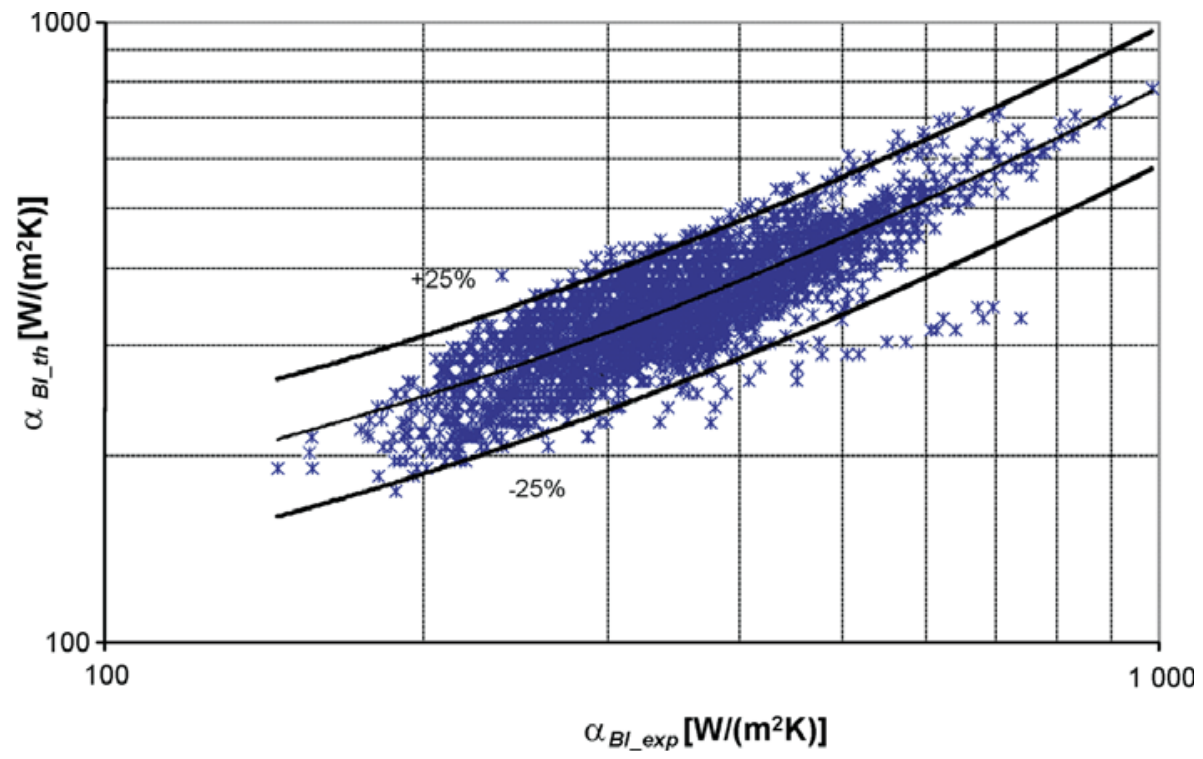

Figure 12. Engineering dependence Eq. (2) for predicting heat transfer coefficient at BI in the minichannel.

\section{Conclusions}

- Flow boiling incipience in minichannels was observed as the 'boiling front' moving upstream when the heat flux density increased. It was accompanied by the occurrence of 'nucleation hysteresis' phenomenon characteristic of the boiling of a liquid with a small wetting angle. It involves a considerable heating surface temperature drop. 
- Pressure, liquid subcooling at the inlet to the minichannel and flow velocity, as well as minichannel depth and spatial orientation affect boiling incipience in the minichannel in the manner shown in the present paper.

- The numbers chosen by the author to develop correlations, namely Re, Bo, and Pr, yield the best results. They are generally considered to denote boiling incipience heat transfer in minichannels of $1-2 \mathrm{~mm}$ depth and different spatial orientation for cooling fluids such as refrigerants.

Acknowledgements The research has been financially supported by the Polish Ministry of Science and Higher Education, Grant No. N N512 354037 for the years 2009-2012.

Received 12 November 2011

\section{References}

[1] Kandlikar S.G., Grande W.J.: Evolution of microchannel flow passagesthermohydraulic performance and fabrication technology. Heat Transfer Eng. $\mathbf{2 5}(2002), 1,3-17$.

[2] Piasecka M., Maciejewska B.: The study of boiling heat transfer in vertically and horizontally oriented rectangular minichannels and the solution to the inverse heat transfer problem with the use of the Beck method and Trefftz functions. Exp. Therm. Fluid Sci. 38(2012), 19-32.

[3] Hozejowska S., Piasecka M., Poniewski M.E.: Boiling heat transfer in vertical minichannels. Liquid crystal experiments and numerical investigations. Int. J. Therm. Sci. 48(2009), 1049-1059.

[4] Piasecka M., Hozejowska S., Poniewski M.E.: Experimental evaluation of flow boiling incipience of subcooled fluid in a narrow channel. Int. J. Heat Fluid Flow 25(2004), 159-172.

[5] Corty C.: PhD thesis, Univ. Michigan, Ann Arbor 1951.

[6] VAn Camp W. M.: PhD thesis, Prude Univ., La Fayette 1952.

[7] BräUer H., Mayinger F.: Onset of nucleate boiling and hysteresis effects under forced convection and pool boiling. Pool and External Flow Boiling ASME-HTD, (V.J. Dhir, A.E. Bergles Eds.), 1992, 15-36.

[8] Bar-Cohen A.: Hysteresis phenomena at the onset of nucleate boiling. Pool and External Flow Boiling ASME-HTD, (V.J. Dhir, Bergles A.E. Eds.), 1992, 1-14.

[9] Bilicki Z.: Latent heat transport in forced boiling flow. Int. J. Heat Mass Transfer 26(1983), 559-565. 
[10] BiLICKI Z.: The relation between the experiment and theory for nucleate forced boiling. In: Proc. 4th World Conf. on Exp. Heat Transfer Fluid Mech. Thermodyn. 2(1997), 571-578.

[11] Bohdal T., Czapp M.: Investigation of zero flow boiling crisis. In: Proc. Nat. Symp. on Heat and Mass Transfer, Warsaw-Jablonna (1986), 34-40 (in Polish).

[12] Bohdal T.: Development of bubbly boiling in channel flow. Exp. Heat Transfer 14(2001), 199-215.

[13] Celata G.P., Cumo M., Setaro T.: Hysteresis phenomena in subcooled flow boiling of well-wetting fluids. Exp. Heat Transfer 5(1992), 253-275.

[14] Peng X.F., Wang B.X.: Forced convection and flow boiling heat transfer for liquid flowing through microchannels., Int. J. Heat Mass Transfer 36(1993), 3421-3427.

[15] Peng X.F., Peterson G.P.: The effect of thermofluid and geometrical parameters on convection of liquids through rectangular microchannels. Int. J. Heat Mass Transfer 38(1995), 755-758.

[16] Peng X.F., Peterson G.P.: Convective heat transfer and flow friction for water flow in microchannel structures. Int. J. Heat Mass Transfer 39(1996), 2599-2608.

[17] Peng X.F., Hu H.Y., WANG B.X.: Boiling nucleation during liquid flow in microchannels. Int. J. Heat Mass Transfer 41(1998), 101-106.

[18] Orozco J., Hanson C.: A study of mixed convection boiling heat transfer in narrow gaps. ASME-HTD 206-2(1992), 81-85.

[19] Chin Y., Hollingsworth D.K., Witte L.C.: A study of convection in an asymmetrically heated duct using liquid crystal thermography. ASME-HTD 357-2(1998), 63-70.

[20] Chin Y., Witte L.C., Hollingsworth D.K.: Investigation of flow boiling incipience in a narrow rectangular channel using liquid crystal thermography. ASME-HTD 357-3(1998), 79-86.

[21] Hollingsworth D.K.: Liquid crystal imaging of flow boiling in minichannels. In: Proc. 2nd Int. Conf. on Microchannels and Minichannels, Rochester, USA, (2004), ASME, 57-66.

[22] Ammerman C., You S.: Enhanced convective boiling of FC-87 in small, rectangular, horizontal channels: heat transfer coefficient and CHF. ASME HTD 357(1998), 225-233.

[23] Wambsganss M.W., France D.M., Jendrzejczyk J.A., Tran T.A.: Boiling heat transfer in a horizontal small-diameter tube. J. Heat Transfer 115(1993), 963972 .

[24] Wambsganss M.W., Jendrzejczyk J.A., France D.M.: Two-phase flow patterns and transitions in a small, horizontal, rectangular channel. Int. J. Multiphase Flow 17(1991), 327-342.

[25] Wambsganss M.W., France D.M.: Small circular and rectangular channels boiling with two refrigerants. Int. J. Multiphase Flow 20(1996), 485-498.

[26] Cortina Diaz M., Boye H., Hapke I., Schmidt J., Stante Y., Zhekov Z.: Investigation of flow boiling in narrow channels by thermographic measurement of local wall temperatures. Microfluid Nanofluid 2(2005), 1-11. 
[27] Brutin D., TAdrist L.: Pressure drop and heat transfer analysis of flow boiling in a minichannel: influence of the inlet condition on two-phase flow stability. Int. J. Heat Mass Transfer 47(2004), 2365-2377.

[28] Reynaud S., Debray F., Franc J. P., Maitre T.: Hydrodynamics and heat transfer in two-dimensional minichannels. Int. J. Heat Mass Transfer 48(2005), 3197-3211.

[29] Shuai J., Kulenovic R., Groll M.: Heat transfer and pressure drop for flow boiling of water in narrow vertical rectangular channels. In: Proc. 1st Int. Conf. on Microchannels and Minichannels, Rochester, USA, (2003), 667-673.

[30] Sobierska E., Kulenovic R., Mertz R., Groll M.: Experimental results of flow boiling of water in a vertical microchannel. Exp. Therm. Fluid Sc. 31(2006), 111-119.

[31] Agostini B., Bontemps A.: Vertical flow boiling of refrigerant R-134a in small channels. Int. J. Heat Fluid Flow 26(2005), 296-306.

[32] Kandlikar S.G.: Fundamental issues related to flow boiling in minichannels and microchannels. Exp. Therm. Fluid Sci. 26(2002), 389-407.

[33] KandlikaR S.G.: Scale effects on flow boiling heat transfer in microchannels: A fundamental perspective. Int. J. Therm. Sci. 49(2010), 1073-1085.

[34] Brutin D., TAdrist L.: Pressure drop and heat transfer analysis of flow boiling in a minichannel: influence of the inlet condition on two-phase flow stability. Int. J. Heat Mass Transfer 47(2004), 2365-2377.

[35] TAdrist L.: Review of two-phase flow instabilities in narrow spaces. In: Proc. ECI Int. Conf. Heat Transfer and Fluid Flow in Microscale, Castelvecchio Pascoli, Italy, (2005), CD-No. 25.

[36] Thome J.R.: Boiling in microchannels: a review of experiment and theory. Int. J. Heat and Fluid Flow 25(2004), 128-139.

[37] Mikielewicz D., Klugmann M., Wajs J.: Experimental investigation of Mshape heat transfer coefficient distribution of R123 flow boiling in small-diameter tubes. Heat Transfer Eng. 33 (2012), 584-595.

[38] Mikielewicz D., Mikielewicz J.: A common method for calculation of flow boiling and flow condensation heat transfer coefficients in minichannels with account of nonadiabatic effects. Heat Transfer Eng. 32(2011), 1173-1181.

[39] Mikielewicz D.: A new method for determination of flow boiling heat transfer coefficient in conventional-diameter channels and minichannels. Heat Transfer Eng. 31(2010), 276-287.

[40] Mikielewicz D., Mikielewicz J., Tesmar J.: Improved semi-empirical method for determination of heat transfer coefficient in flow boiling in conventional and small diameter tubes. Int. J. Heat Mass Transfer 50(2007), 3949-3956.

[41] Dutkowski K.: Experimental investigations of Poiseuille number laminar flow of water and air in minichannels. Int. J. Heat Mass Transfer 51(2008), 5983-5990.

[42] Dutkowski K.: Influence of the flashing phenomenon on the boiling curve of refrigerant R-134a in minichannels. Int. J. Heat Mass Transfer 53(2010), 1036-1043. 
[43] Dutkowski K.: Air-water two-phase frictional pressure drop in minichannels. Heat Transfer Eng. 31(2010), 321-330.

[44] Dutkowski K.: Two-phase pressure drop of air-water in minichannels. Int. J. Heat Mass Transfer 52(2009), 5185-5192.

[45] Piasecka M., Maciejewska B.: Application of the finite element method to the determining of boiling heat transfer coefficient for minichannel flow. Arch. Thermodyn. 34(2013).

[46] Piasecka M., Poniewski M. E.: Liquid crystal thermography applied to investigations into heat transfer in minichanels. Metrol Meas. Sys. 11(2004), 259-274.

[47] Piasecka M., Poniewski M. E.: Hysteresis phenomena at the onset of subcooled nucleate flow boiling in microchannels. Heat Transfer Eng. J. 25(2004), 44-51.

[48] Tноме J.R.: Enhanced Boiling Heat Transfer. Hemisphere, New York-WashingtonPhiladelphia-London 1990.

[49] Bohdal T.: Development of bubbly boiling in channel flow. Exp. Heat Transfer 14(2001), 3, 199-215. 